\title{
Adaptación del Método Bligh \& Dyer a la Extracción de Lípidos de Microalgas Colombianas para la Producción de Biodiesel de Tercera Generación
}

\author{
Adaptation Method Bligh \& Dyer a Lipid Extraction \\ of Colombian Microalgas Biodiesel Production for \\ THIRD GENERATION
}

\section{González Delgado Ángel', Galindo Leisslly², González Silvia ${ }^{3}$, Peralta Ruiz Yeimmy ${ }^{4}$, Kafarov Viatchesla ${ }^{5}$}

\author{
${ }^{1}$ Escuela de Ciencia Agrícolas y Pecuarias, Universidad Nacional Abierta y a Distancia-UNAD, \\ Bucaramanga, Colombia, angeld.gonzalez@unad.edu.co \\ 2 Universidad Industrial de Santander-UIS, Bucaramanga, Colombia, \\ investigacion@greenideaingenieria.com, \\ ${ }^{3}$ Universidad Nacional Abierta y a Distancia-UNAD, Bucaramanga, Colombia, \\ andagon@gmail.com \\ ${ }^{4}$ Escuela de Ciencias Básicas Tecnología e Ingeniería, Universidad Nacional Abierta y a Distancia-UNAD, \\ Bucaramanga, Colombia, yeimmy.peralta@unad.edu.co \\ ${ }^{5}$ Centro de Investigación para el Desarrollo Sostenible en Industria y Energía, Universidad Industrial \\ de Santander, Bucaramanga, Colombia, cisyc@uis.edu.co
}

Recibido: 24/10/2011 • Aprobado: 15/12/2011

\section{RESUMEN}

En la cadena de producción de biodiesel a partir de microalgas, las etapas de disrupción celular y extracción de lípidos son importantes para la obtención de triglicéridos que pueden ser transesterificados a biodiesel y glicerina. En este trabajo se adaptó el método propuesto por Bligh \& Dyer, a la extracción de lípidos de microalgas nativas, evaluando conjuntamente el pretratamiento organosolv o hidrólisis ácida como mecanismo de disrupción celular y utilizando el cloroformo $\left(\mathrm{CHCl}_{3}\right)$, el metanol $\left(\mathrm{CH}_{3} \mathrm{OH}\right)$ y el agua $\left(\mathrm{H}_{2} \mathrm{O}\right)$, como solventes.

En la parte experimental, se emplearon las especies Botryococcus braunii, Nannocloropsis, Closterium, Guinardia y Amphiprora. La adaptación del método consistió en determinar las mejores condiciones de extracción, tales como: relación biomasa/solvente 1:20, relación inicial de solventes $\mathrm{CHCl}_{3}: \mathrm{CH}_{3} \mathrm{OH}: \mathrm{H}_{2} \mathrm{O}$ (1:2:0), agitación a $5000 \mathrm{rpm}$ durante 14 minutos y centrifugación a $3400 \mathrm{rpm}$ durante 15 minutos. 
Luego de realizar la extracción, los mecanismos de disrupción celular aplicados permitieron obtener extractos más ricos en lípidos, pero desfavorecieron significativamente los porcentajes totales de la misma. Finalmente, los perfiles de ácidos grasos mostraron que la especie Botryococcus braunii contiene mayor porcentaje de área de acilgliceroles aptos para la producción de biodiesel.

Palabras clave: biomasa, disrupción celular, extracción, lípidos, método Bligh \& Dyer, microalgas

\section{AbStRact}

In the biodiesel production process from microalgae, the cell disruption and lipid extraction stages are important for obtaining triglycerides that can be transesterified to biodiesel and glycerol. In this work, the Bligh \& Dyer method was adapted for lipid extraction from native microalgae using organosolv pretreatment or acid hydrolysis as cell disruption mechanism for improve the extraction process. Chloroform-methanol-water are the solvents employed in the Bligh \& Dyer extraction method. The microalgae species Botryococcus braunii, Nannocloropsis, Closterium, Guinardia y Amphiprora were employed for the experimental part. Adaptation of the method was found the best extraction conditions, these were: 1:20 biomass/solvent ratio, initial ratio solvents $\mathrm{CHCl}_{3}: \mathrm{CH}_{3} \mathrm{OH}: \mathrm{H}_{2} \mathrm{O}$ (1:2:0), stirring conditions of $5000 \mathrm{rpm}$ for 14 minutes and centrifuge of $3400 \mathrm{rpm}$ for 15 minutes. The cell disruption mechanisms allowed to obtain extracts with high lipid content after performing the extraction with Bligh \& Dyer method, but decreases significantly the total extraction yield. Finally, the fatty acids profiles showed that Botryococcus braunii specie contains higher acylglycerol percentage area suitable for the production of biodiesel.

Keywords: biomass, bligh \& dyer method, cell disruption, extraction, lipids, microalgae

\section{INTRODUCCIÓN}

El cambio climático es uno de los grandes desafíos del Siglo XXI debido a que sus impactos son globales y cada vez más severos sobre la estabilidad económica, social y ambiental del planeta. En respuesta a esta problemática, las políticas ambientales han favorecido el incremento del uso de biocombustibles en el mundo, principalmente aquellos que pueden sustituir los combustibles fósiles utilizados en el transporte vehicular [1]. Actualmente, los biocombustibles en los que se ha invertido más esfuerzo son el etanol, a partir de caña de azúcar y maíz, y el biodiesel, a partir de fuentes oleaginosas. Sin embargo, la sustentabilidad de su producción se ha visto fuertemente cuestionada por la gran demanda de cultivos que requieren para su obtención [2]. Para lograr sustentabilidad económica y ambiental, es importante que el proceso de producción de biocombustibles no sólo sea renovable, sino que también contribuya al secuestro de $\mathrm{CO}_{2}$ atmosférico [3]. Por lo anterior, los biocombustibles de tercera generación, derivados principalmente de microbios y microalgas, se consideran una alternativa viable de fuente de energía porque no presentan los inconvenientes asociados a los biocombustibles de primera y segunda generación [4].

Las microalgas contribuyen de manera importante a la fijación de $\mathrm{CO}_{2}$ y pueden producir una amplia gama de biocombustibles, tales como: biodiesel, bioetanol, biometano y biohidrógeno [5]. Así mismo, tienen el potencial de asegurar una gran producción de biodiesel por unidad de 
área debido a su alto contenido de lípidos, el cual supera a todas las fuentes de biodiesel utilizadas en la actualidad [6]. El objetivo principal de este trabajo, fue adaptar el método de Bligh \& Dyer [7] a la extracción de lípidos de microalgas nativas, evaluando previamente mecanismos de disrupción celular.

\section{Materiales y Métodos}

Las especies de microalgas utilizadas fueron suministradas por la Corporación Instituto de Morrosquillo (Punta Bolívar, Colombia); se cultivaron en estanques abiertos, se cosecharon por floculación, se secaron al sol y se refrigeraron hasta su utilización; las especies trabajadas fueron: Closterium 200 ppm Al $2\left(\mathrm{SO}_{4}\right)_{3}$, para determinar la relación biomasa/solvente; Closterium de agua dulce en el diseño experimental; Guinardia, para seleccionar el mejor pretratamiento, y Amphiprora, para verificar la influencia del pretratamiento en la extracción. Adicionalmente, el Instituto Colombiano del Petróleo suministró las especies Nannocloropsis, cosechada por floculación y secada hasta su utilización, y Botryococcus braunii, la cual se secó por liofilización. Estas dos especies se emplearon para determinar la influencia de la adición de agua en la primera agitación.

Se usaron distintas especies de microalgas en diferentes partes del desarrollo experimental debido a la no disponibilidad de biomasa, lo cual generó resultados poco rígidos. Sin embargo, este trabajo brinda una primera aproximación de la implementación del método de Bligh \& Dyer [7], a un grupo heterogéneo de especies de microalgas nativas, dentro del proyecto "Bioprospección de microalgas colombianas para la producción de biodiesel". Los reactivos empleados en la etapa de disrupción celular fueron: metanol, ácido sulfúrico y ácido clorhídrico y en la etapa de extracción, como solventes, se utilizaron metanol y cloroformo. Además, durante todo el desarrollo experimental se empleó agua destilada. La biomasa previamente seca se sometió a pretratamiento organosolv [8] o hidrólisis ácida; luego se filtró al vacío y se lavó con abundante agua destilada para eliminar los residuos de ácido; finalmente, se secó para su posterior extracción.

El proceso de extracción mediante el método Bligh \& Dyer Fig. 1, contempla las etapas de agitación, centrifugación, separación y volatilización [7]. En la etapa de agitación se evaluaron dos proporciones de biomasa/solvente 1:10 [7], [9] y 1:20 con base en los resultados de las pruebas preliminares: el efecto de la adición de agua en la primera parte de la agitación, y el efecto del tiempo y de la frecuencia de homogenización, según un diseño experimental. La centrifugación se llevó a cabo durante 15 minutos y se evaluó la máxima frecuencia reportada por la literatura $(2500 \mathrm{rpm})$ (Instituto de salud pública de Chile) y la máxima permitida por el equipo disponible (3400 rpm) en el Laboratorio de Biomasa de la Universidad Industrial de Santander. La separación de las fases se realizó extrayendo la fase superior $\left(\mathrm{CH}_{3} \mathrm{OH}-\mathrm{H}_{2} \mathrm{O}\right)$ de los tubos de centrífuga, mientras que la fase inferior (biomasa/lípidos- $\mathrm{CHCl}_{3}$ ) se filtró por gravedad. Finalmente, el extracto lipídico se dejó volatilizar hasta peso constante para su cuantificación. Para cada experimento se realizaron como mínimo dos réplicas con el fin de dar reproducibilidad a los resultados. Los extractos lipídicos de las especies Nannocloropsis y Botryococcus braunii se caracterizaron por medio de cromatografía de gases "Análisis FAMES" (Fatty Acid Methyl Esters), empleando un cromatógrafo Agilent 7890 con detector FID y una columna DB $5-\mathrm{Ht}$ de $15 \mathrm{~m}$.

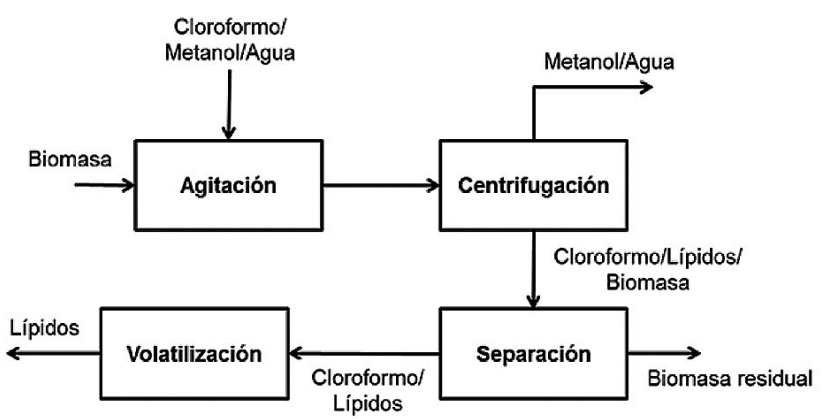

Fig 1. Etapas del proceso de extracción Bligh \& Dyer 


\section{Resultados y Análisis}

En la etapa de agitación se evaluó inicialmente la relación biomasa/solvente 1:10 de la cual no se obtuvo ningún extracto, debido a que la velocidad de volatilización del cloroformo fue mayor a la velocidad de filtración de la mezcla, quedando toda la biomasa retenida en la etapa de filtración. No obstante, al realizar la extracción con una relación biomasa/ solvente de 1:20 se superó este inconveniente, por lo que se decidió mantener esta para pruebas posteriores. Por otra parte, al trabajar con una frecuencia de 2500 rpm en la etapa de centrifugación no se logró separar totalmente las fases, mientras que con una frecuencia de 3400 rpm se identificó el sistema bifásico formado por una fase superior metanol-agua e inferior cloroformo-lípidos-biomasa. Por esta razón, para pruebas posteriores se decidió centrifugar a 3400 rpm durante 15 minutos.

El porcentaje de extracto lipídico obtenido para dos especies de microalgas de bioprospección nacional, con y sin adición de agua en la primera parte de la etapa de agitación, se muestra en la Tabla 1 donde se observa, que la adición de agua disminuyó el porcentaje de extracción para las especies Botryococcus braunii y Nannocloropsis en un $15 \%$ y $40 \%$, respectivamente. Esto se debe a que el agua es soluble con el metanol e insoluble con el cloroformo y los lípidos, lo cual afecta la solubilidad cloroformo - metanol y dificulta la extracción de los lípidos. Con base en estos resultados se concluyó que para la adaptación de la metodología Bligh \& Dyer, a la extracción de lípidos de biomasa de microalgas, no es conveniente adicionar agua en la primera parte de la agitación. Para estas pruebas la relación biomasa/agua se mantuvo en 1/3,2.

TABLA I

Resultados del Efecto de Adicionar Agua en la Primera Parte de la Agitación.

\begin{tabular}{cccc}
\hline Especie & $\begin{array}{c}\text { Peso de la } \\
\text { muestra (g) }\end{array}$ & Agua (ml) & $\begin{array}{c}\text { \% Extracto } \\
\text { lipídico }\end{array}$ \\
\hline Botrycoccus & 5 & - & 5,6 \\
Braunii & 5 & 16 & 4,74 \\
Nannocloropsis & 3,5 & - & 1,45 \\
& 10 & 32 & 0,89 \\
\hline
\end{tabular}

Para estudiar el efecto de la frecuencia de agitación sobre el rendimiento de la extracción, se le realizó a la especie Closterium, disrupción celular, mediante pretratamiento organosolv; la extracción se llevó a cabo homogenizando la mezcla biomasa/ solvente durante 14 minutos a frecuencias de 5000 , 8000 y 11000 rpm. En la Fig. 2 se observa que un aumento en la frecuencia de agitación disminuye el porcentaje de extracto lipídico; este resultado coincide con lo reportado por [10], quienes evaluaron la extracción asistida con ultrasonido aplicando frecuencias entre 19 y $300 \mathrm{kHz}$, obteniendo mayores rendimientos de extracción a bajas frecuencias. Por lo tanto, se decidió efectuar un diseño experimental para analizar conjuntamente las variables tiempo y frecuencia de agitación.

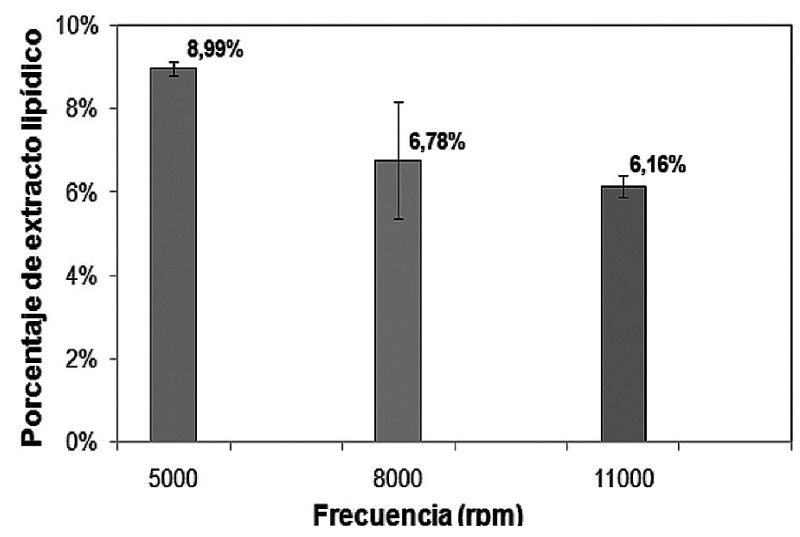

Fig 2. Efecto de la frecuencia de agitación sobre el porcentaje de extracción.

Las variables estudiadas en el diseño experimental fueron: la sumatoria de tiempos en la homogenización (min) y la frecuencia de agitación (rpm).

En la Tabla 2 se presentan los valores de los niveles seleccionados para cada una de las variables del diseño experimental.

TABLA II

Valores y Niveles de las Variables Estudiadas.

\begin{tabular}{cccc}
\hline \multirow{2}{*}{ FACTORES } & \multicolumn{3}{c}{ NIVELES } \\
\cline { 3 - 5 } & -1 & 0 & 1 \\
\cline { 3 - 4 } Tiempo (min) & 14 & 23 & 32 \\
Frecuencia (rpm) & 5000 & 8000 & 11000 \\
\hline
\end{tabular}


La matriz de diseño experimental y sus respectivos porcentajes de extracto lipídico obtenidos se muestran en la Tabla 3. Los mejores resultados se encuentran al nivel más bajo de cada variable y corresponden a los experimentos 1 y 6 .

TABLA III

Matriz del Diseño Experimental y Porcentajes de EXTRACTO LIPÍDICO OBTENIDOS DURANTE LA EXTRACCIÓN.

\begin{tabular}{cccc}
\hline No Experimento & Frecuencia & Tiempo & $\begin{array}{c}\% \\
\text { Extracto } \\
\text { lipídico }\end{array}$ \\
\hline 1 & -1 & -1 & $9,13 \%$ \\
2 & 1 & -1 & $6,34 \%$ \\
3 & -1 & 1 & $5,30 \%$ \\
4 & 1 & 1 & $4,46 \%$ \\
5 & 0 & 0 & $6,43 \%$ \\
6 & -1 & -1 & $8,86 \%$ \\
7 & 1 & -1 & $5,98 \%$ \\
8 & -1 & 1 & $4,87 \%$ \\
9 & 1 & 1 & $4,03 \%$ \\
10 & 0 & 0 & $5,21 \%$ \\
\hline
\end{tabular}

En el diagrama de Pareto Fig. 3a, se observa que las variables tiempo, frecuencia y su interacción, presentan efectos significativos sobre la extracción, debido a que todos los bloques pasan el umbral (línea interna vertical gruesa). Además, se puede inferir que las variables tiempo y frecuencia presentan efectos negativos sobre el rendimiento de la extracción de lípidos de microalgas, siendo el tiempo el factor que más afecta negativamente la variable de respuesta. Por último, cabe destacar que la combinación entre las variables independientes tiene un efecto positivo sobre la variable de respuesta estudiada. Como complemento, se ilustra en la Fig. 3b un análisis cuantitativo del efecto de las variables estudiadas sobre el porcentaje de extracto, en el cual se verifica, que el tiempo es el factor más influyente en el rendimiento de la extracción, ya que a menores tiempos de agitación (14 minutos) se obtienen mayores porcentajes de extracción $(7-7,6 \%)$, mientras que trabajando a frecuencias de 5000 rpm se alcanzan menores rendimientos (6,6-7\%).
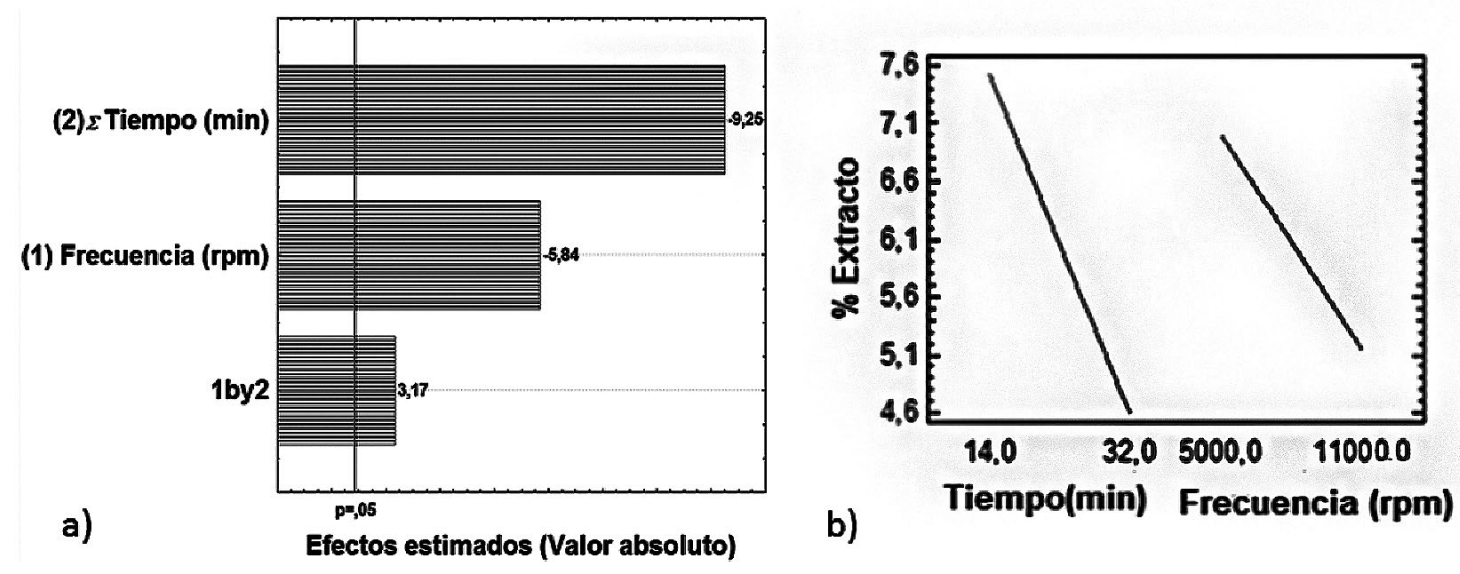

Fig 3. a) Efecto de la frecuencia de homogenización y tiempo de agitación sobre el porcentaje de extracto lipídico,

b) Gráfico de efectos principales para el porcentaje de extracto lipídico.

La interacción entre el tiempo y la frecuencia de agitación se puede ver en la Fig. 4 en la que la superficie y curva de nivel presentan una región con mayor porcentaje de extracto lipídico y otra con menor porcentaje denotadas por las zonas oscuras y claras, respectivamente. Se puede ob- servar, entonces, que el porcentaje de extracto lipídico se maximiza cuando las variables tiempo y frecuencia de agitación se encuentran en el nivel más bajo dentro de la región experimentada; es decir, 14 minutos y $5000 \mathrm{rpm}$. 

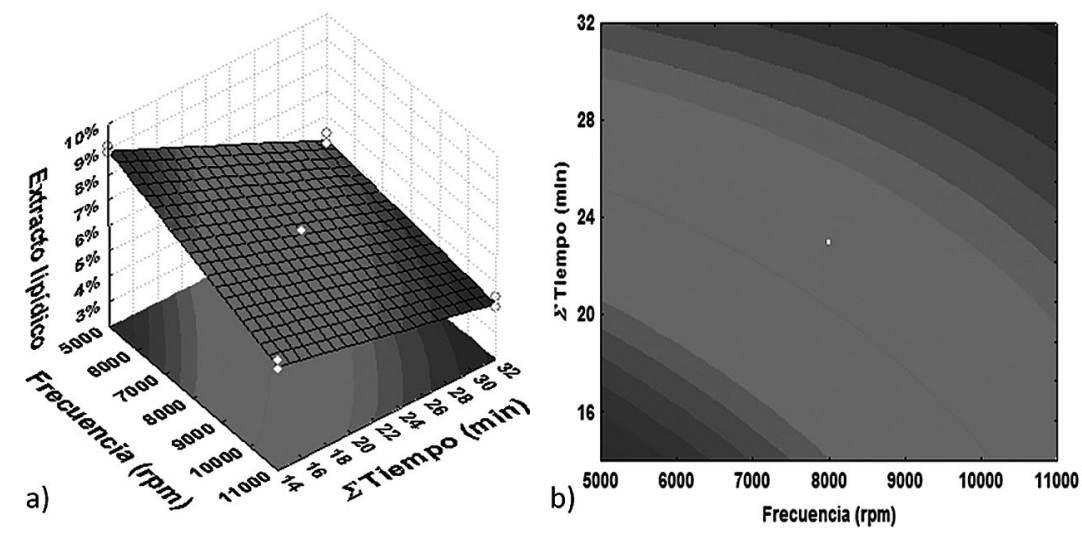

Fig 4. Efecto de la frecuencia y tiempo de agitación sobre el porcentaje de extracto lipídico. a) Diagrama superficie de respuesta b) Diagrama de contorno.

Teniendo en cuenta que la pared celular de las microalgas se destruye por la degradación de los polisacáridos presentes en la biomasa, y que estos y otros componentes de la matriz sólida son solubles en el licor de hidrólisis, un gran porcentaje de la biomasa sometida al proceso de lisis celular pasa a formar parte de este licor, disminuyendo la biomasa sometida a extracción. El porcentaje de biomasa que pasa a formar parte del licor después de la etapa de disrupción celular se muestra en la Fig. 5 en la cual se observa que la fracción másica de los componentes hidrosolubles en el licor de hidrólisis varía según la especie de micro alga y el método de disrupción celular aplicado. Por ejemplo, para el caso de la especie Guinardia, el porcentaje de biomasa que pasa a formar parte del licor de hidrólisis es mayor con pretratamiento organosolv, en comparación con la hidrólisis ácida.

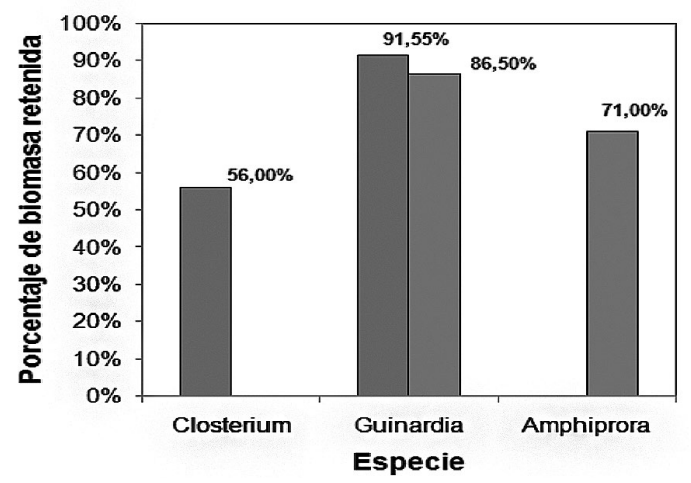

Fig 5. Porcentaje de biomasa que pasa a formar parte del licor de disrupción celular

$\square$ Pretratamiento Organosolv, $\square$ Hidrólisis ácida.
Para la especie Guinardia se evaluaron dos métodos de disrupción celular: hidrólisis ácida y pretratamiento organosolv, los cuales, como se puede observar en la Fig. 6a, no incrementaron el porcentaje de extracto lipídico. Con base en estos resultados, el pretratamiento organosolv se descartó para pruebas posteriores, por una parte, debido a los bajos porcentajes de extractos lipídicos obtenidos y, por otra, a la dificultad en el desarrollo de la extracción. Mientras que la disrupción celular con hidrólisis ácida, aunque reportó una disminución del $32 \%$ en el rendimiento, continuó siendo objeto de estudio, ya que facilitó las etapas de centrifugación y filtración durante la extracción. Se realizaron, posteriormente, nuevas pruebas, aplicando hidrólisis ácida a la especie Amphiprora Fig. 6b, con el fin de verificar que el efecto negativo de este método se presentaba también en otras especies; se obtuvo, entonces, una disminución del $55 \%$ en el rendimiento de la extracción. Los porcentajes de extracto lipídico se calcularon con base en la biomasa, antes de realizar la disrupción celular. 

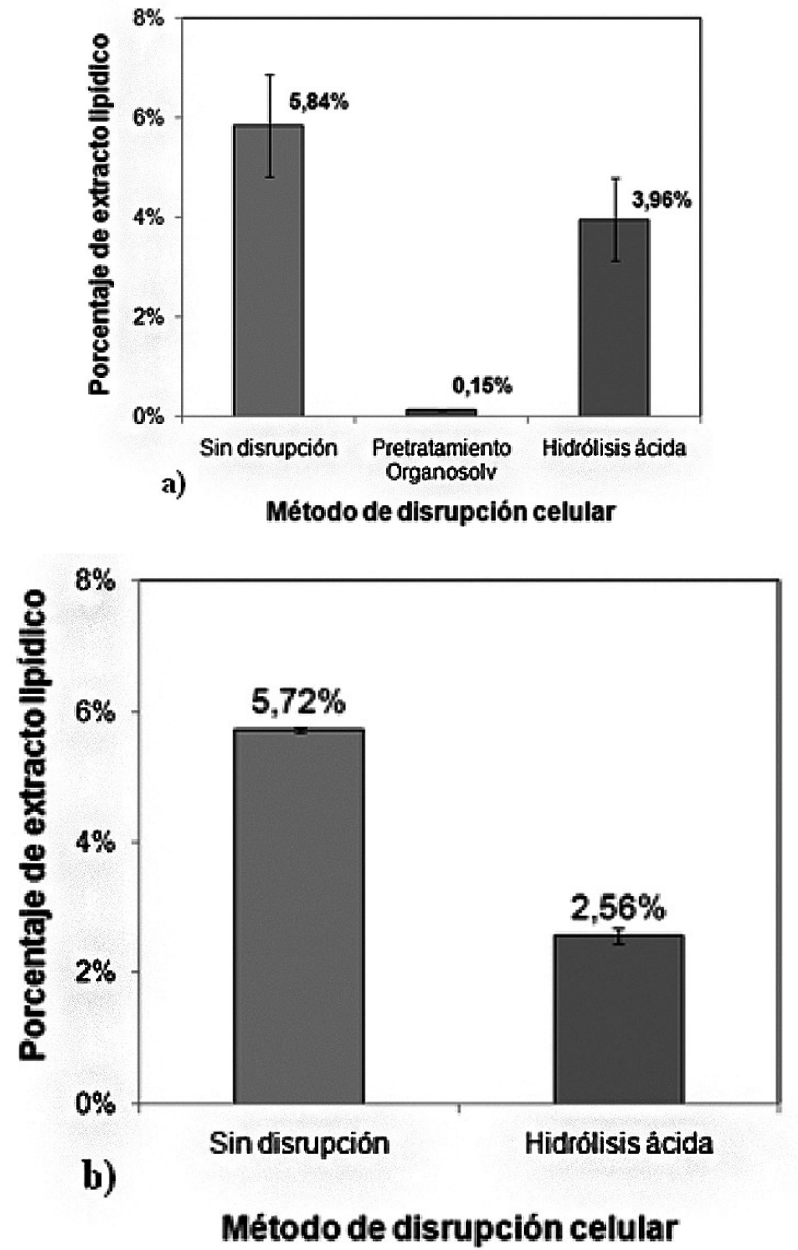

Fig 6. Efecto de la disrupción celular sobre el porcentaje de extracción a las condiciones óptimas de extracción. a) Especie Guinardia

b) Especie Amphiprora.

Los bajos rendimientos de extracción empleando biomasa con disrupción celular, respecto de biomasa sin disrupción celular, se deben a que el método de extracción Bligh \& Dyer, en particular, extrae, además de lípidos, cantidades significativas de componentes no lipídicos [11]. Al aplicar previamente un método de disrupción celular, estos componentes no lipídicos pasan a formar parte del licor de hidrólisis, obteniéndose un extracto lipídico más puro, en comparación con la extracción en la que se utiliza biomasa sin disrupción celular. Es decir, que la aplicación de un método de disrupción celular permite obtener extractos más puros luego de realizar la extracción de lípidos con el método Bligh \& Dyer, aunque se obtengan menores porcentajes de esta. La eficiencia de la extracción que se muestra en la Tabla 4 se calculó con base en los porcentajes de lípidos totales para cada especie, de la siguiente manera:

$$
E=\left(\frac{B}{A}\right) 100 \%
$$

Donde $E$ es la eficiencia de la extracción, $A$ es el porcentaje de lípidos totales y $\mathrm{B}$ es el rendimiento obtenido en este estudio.

TABLA IV

EFICIENCIA DE LA EXTRACCIÓN PARA VARIAS ESPECIES DE MICROALGAS.

\begin{tabular}{lccc}
\hline \multicolumn{1}{c}{ Especie } & $\begin{array}{c}\text { Lípidos } \\
\text { totales }\end{array}$ & $\begin{array}{c}\text { Lípidos } \\
\text { extrídos* }\end{array}$ & Eficiencia \\
\hline Nannocloropsis $^{a}$ & $11 \%$ & $1,50 \%$ & $13 \%$ \\
Botryococcus braunit $^{b}$ & $15 \%$ & $5,60 \%$ & $37 \%$ \\
Closterium $^{*}$ & $22 \%$ & $9,10 \%$ & $41 \%$ \\
Amphiprora $^{\alpha}$ & $12 \%$ & $5,70 \%$ & $48 \%$ \\
Guinardia $^{*}$ & $7 \%$ & $5,80 \%$ & $87 \%$ \\
\hline
\end{tabular}

ayb Extracciones a $8000 \mathrm{rpm}$.

- Extracciones con disrupción celular

dys Extracciones sin disrupción celular

* Método adaptado por los autores

La especie Nannocloropsis presentó el rendimiento más bajo; Closterium, Amphiprora y Botryococcus se acercaron a un rendimiento del $50 \%$ y los mejores resultados se obtuvieron con Guinardia. Este alto rendimiento fue consecuencia de la rápida separación entre el extracto lipídico y el sólido en la etapa de filtración. Los cromatogramas de los análisis de FAMES (Fatty Acid Methyl Esters) de los extractos lipídicos para las especies Botryococcus braunii y Nannocloropsis ampliados durante los primeros 7 minutos se muestran en las Fig. 7 y 8. 


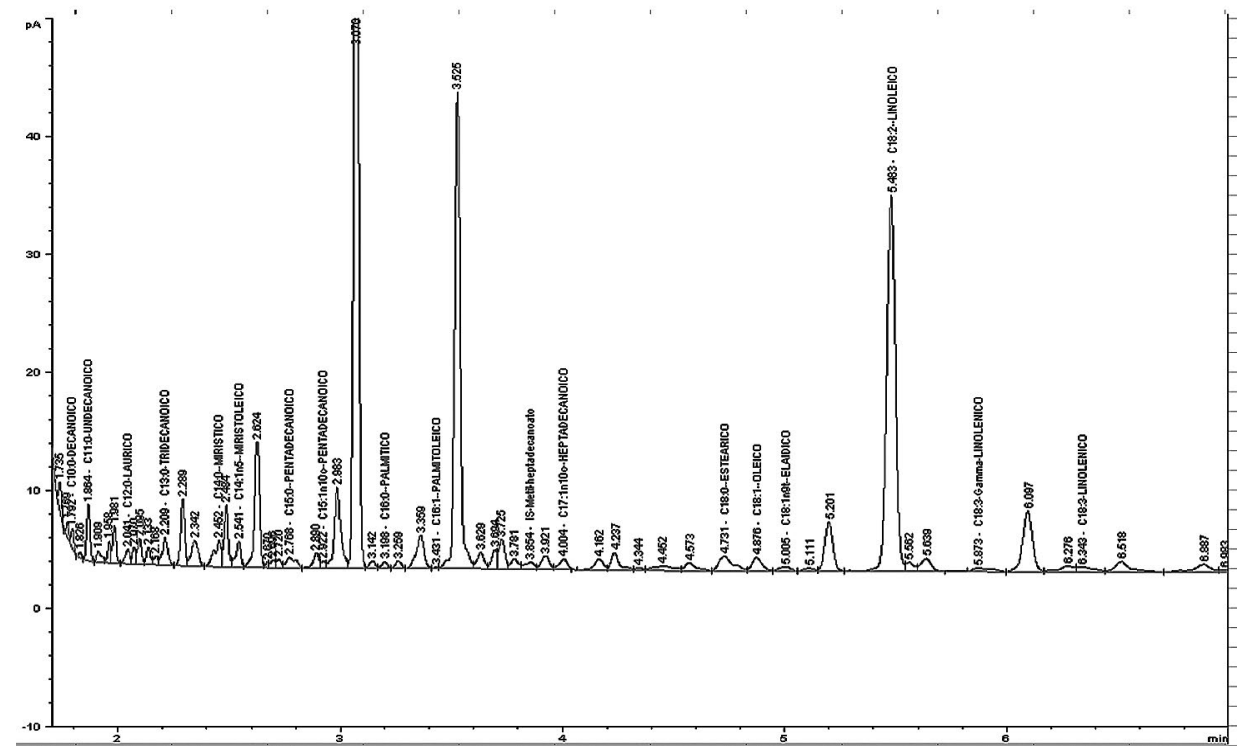

Fig 7. Cromatograma (análisis FAMES) ampliado durante los primeros 7 minutos del extracto lipídico de Botryococcus braunii sin disrupción celular.

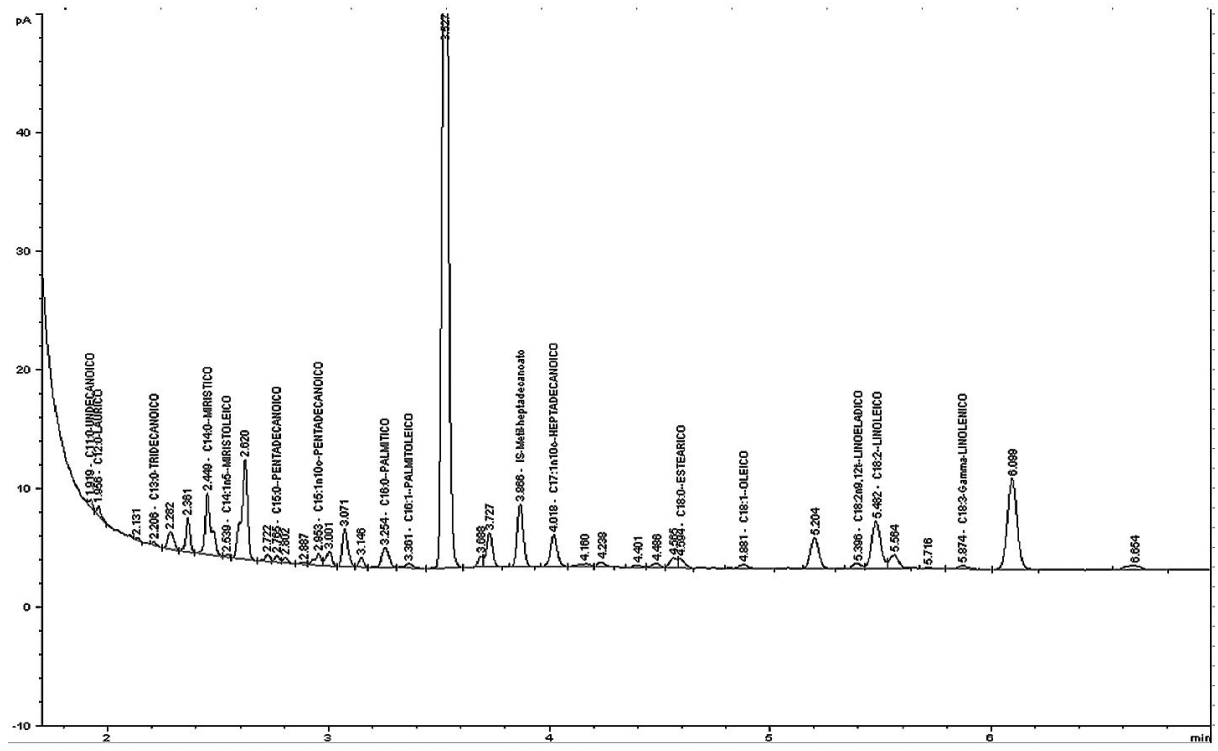

Fig 8. Cromatograma (análisis FAMES) ampliado de los primeros 7 minutos del extracto lipídico de Nannocloropsis sin disrupción celular.

En el perfil de los ácidos grasos para las especies Botryococcus braunii y Nannocloropsis Tabla 5 se observa que el método Bligh \& Dyer [12], extrae ácidos grasos saturados (verde) e insaturados (azul), así como grasos comunes en aceites vegetales (amarillo) y animales (rojo); ácidos grasos poco comunes (gris) y ácidos grasos esenciales (naranja) poliinsaturados, comúnmen- te llamados omega-3 (Linolénico), omega-6 (Linolénico) y omega-9 (Oléico). También se muestra que el $34.6 \%$ y el $12,5 \%$ para las especies Botryococcus braunii y Nannocloropsis corresponden respectivamente al porcentaje de área de acilgliceroles presentes en los extractos lipídicos. Estos acilgliceroles pueden ser aptos para la producción de biodiesel. 
TABLA V

Perfil de Ácidos Grasos Presentes en las Especies BotryococCus BRAUNII Y NANNOCLOROPSIS.

\begin{tabular}{|c|c|c|c|}
\hline \multirow{2}{*}{$\begin{array}{c}\text { ACIDO } \\
\text { GRASO } \\
\text { Nome nclatura }\end{array}$} & \multicolumn{2}{|c|}{ Especie } & \multirow{2}{*}{$\begin{array}{c}\text { Tipo de ácido } \\
\text { graso }\end{array}$} \\
\hline & $\begin{array}{c}\text { Botyoococcus } \\
\text { braunï }\end{array}$ & Nern ocloropsis & \\
\hline C6:0 & $30,30 \%$ & $0,00 \%$ & \\
\hline C8:0 & $0,90 \%$ & $0,00 \%$ & \\
\hline C10:0 & $0,50 \%$ & $0,00 \%$ & \\
\hline C11:0 & $2,40 \%$ & $0,00 \%$ & \\
\hline C12:0 & $0,80 \%$ & $0,00 \%$ & \\
\hline C13:0 & $0,40 \%$ & $0,00 \%$ & \\
\hline C14:0 & $0,00 \%$ & $21,30 \%$ & \\
\hline Cl5:0 & $1,30 \%$ & $1,70 \%$ & \\
\hline C15:1nl0c & $6,60 \%$ & $4,20 \%$ & \\
\hline C16:0 & $0,60 \%$ & $7,90 \%$ & \\
\hline C 17:0 & $0,80 \%$ & $21,60 \%$ & \\
\hline C18:1 & $1,70 \%$ & $1,80 \%$ & \\
\hline C18: $\ln 9 t$ & $0,60 \%$ & $0,00 \%$ & \\
\hline C 18:2 & $40,30 \%$ & $23,80 \%$ & \\
\hline C 18:3 & $0,70 \%$ & $2,00 \%$ & \\
\hline C 18:3 & $1,10 \%$ & $0,00 \%$ & \\
\hline C20:0 & $0,70 \%$ & $0,00 \%$ & \\
\hline $\mathrm{C} 20: 1$ & $0,60 \%$ & $0,70 \%$ & \\
\hline C20:2nl 1,14c & $4,20 \%$ & $0,00 \%$ & \\
\hline$C 21: 0$ & $0,50 \%$ & $0,60 \%$ & \\
\hline $\mathrm{C} 20: 3$ & $1,00 \%$ & $0,00 \%$ & \\
\hline C20:5 & $0,80 \%$ & $0,00 \%$ & \\
\hline $\mathrm{C} 22: 0$ & $0,40 \%$ & $0,00 \%$ & \\
\hline C22:2 & $0,80 \%$ & $1,00 \%$ & \\
\hline C24:0 & $0,40 \%$ & $6,80 \%$ & \\
\hline C24: 1 & $0,20 \%$ & $3,50 \%$ & \\
\hline C24: 1 & $0,40 \%$ & $3,00 \%$ & \\
\hline TotalFA, \% & $100 \%$ & $100 \%$ & \\
\hline $\begin{array}{l}\text { Acilgliceroles, } \\
\text { \%área }\end{array}$ & $34,60 \%$ & $12,50 \%$ & \\
\hline
\end{tabular}

\section{Conclusiones}

El método propuesto por Bligh \& Dyer se adaptó a la extracción de lípidos de microalgas nativas, en la que las mejores condiciones de operación fueron: relación biomasa/solvente 1:20, frecuencia de homogenización 5000 rpm, tiempo total de homogenización 14 minutos, frecuencia y tiempo de centrifugación 3400 rpm y 15 minutos, respectivamente. Además, la adición de agua en la primera parte de la agitación facilitó la filtración, aunque disminuyó el porcentaje de extracción de aceite en un rango entre $15-40 \%$, dependiendo de la especie de microalga trabajada.
La hidrólisis ácida como método de disrupción celular permite obtener extractos más ricos en lípidos luego de realizar la extracción con la metodología propuesta, si bien se desfavorece significativamente el porcentaje total de extracto lipídico, en un rango entre el 32 y 55\%, según la especie de microalga trabajada. El análisis FAMES mostró que la especie Botryococcus braunii contiene mayor porcentaje de área de acilgliceroles $(34,6 \%)$ aptos para la producción de biodiesel en comparación con la especie Nannocloropsis (12,5\%).

Finalmente, es de resaltar que este trabajo es pionero en Colombia y es una aproximación al estudio y adaptación del método propuesto por Bligh \& Dyer, a la extracción de lípidos de microalgas para la producción de biodiesel. Sin embargo, se recomienda aplicar la metodología propuesta en este trabajo a otras especies de microalgas nativas, evaluando conjuntamente filtración al vacío o membranas con el fin de incrementar la pureza del extracto lipídico y los rendimientos de la extracción. Así mismo, buscar métodos alternativos para identificar los componentes no lipídicos que generan ruido en los cromatogramas, como pueden ser las fracciones de biomasa solubles en cloroformo.

\section{Agradecimientos}

Los autores agradecen al Ministerio de Agricultura por su apoyo mediante el proyecto "Bioprospección de microalgas colombianas para la producción de biodiesel" con código 2008D32006-6710; al Instituto Colombiano del Petróleo y al Programa Iberoamericano de Ciencia y Tecnología para el Desarrollo, proyecto internacional "New technologies for biofuels production" código UNESCO 330303, 332205, 530603, 330399. 


\section{REFERENCIAS}

[1] A. Demirbas, "Biofuels sources, biofuel policy, biofuel economy and global biofuel projections". Energy Conversion and Management, Vol. 49, pp. 21062116., 2008.

[2] S. Majer, F. Mueller-Langer, V. Zeller and M. Kaltschmitt. "Implications of biodiesel production and utilization on global climate a literature review". European Journal of Lipid Science Technology, vol. 111, No. 8, pp.747-762, 2009.

[3] P. Schenk, S. Thomas-Hall, E. Stephen, U. Marx, J. Mussgnug, C. Posten, O. Kruse, and B. Hankamer. "Second generation biofuels: high-efficiency microalgae for biodiesel production". Bioenergy Research, vol. 1, No. 1, pp. 20-43, 2008.

[4] N. Singh and A. Singh. "Production of lipids biofuels from renewable resources". Progress in energy and combustion science, pp. 1-17, 2010.

[5] J. Rosenberg, G. Oylerl, L. Wilkinson and M. Betenbaugh. "A green light for engineered algae: redirecting metabolism to fuel a biotechnology revolution"' Current Opinion in Biotechnology, vol. 19, pp. 430436, 2008.

[6] Chisti Y. "Biodiesel from microalgae." Biotechnology Advances, vol. 25, pp. 294-306, 2007.
[7] E. Bligh and W. Dyer. "A rapid method of total lipid extraction and purification." Journal Biochemical Physiology, vol. 37, No. 8, pp. 911-917, 1959.

[8] M. Jaramillo and N. Mantilla. Estudio del método de pretratamiento químico etanol-NaOH para la obtención de azúcares reductores a partir de microalgas, como vía a la producción de bioetanol. Universidad Industrial de Santander, Bucaramanga, 25 p., 2010.

[9] A. Dominguez J. Fábregas and A. Otero. "Astaxantina, el oro rojo de la microalga" Haematococcus Pluvialis. Algas: Boletín Española de ficología: pp. 160-167, 2006.

[10] G. Cravotto, L Boffa, S. Mantegna, P. Perego, M. Avogadro and P. Cintas 2. "Improved extraction of vegetable oils under high-intensity ultrasound and/or microwaves". Ultrasonics sonochemistry, vol. 15, No. 5, pp. 898-902, 2008.

[11] S., Lee B. Yoon, and H. Oh 1. "Rapid method for the determination of lipid from the green alga Botryococcus braunii." Biotechnology Techniques, vol. 12, No. 7, pp. 553- 556, 1998.

[12] Determinación de grasa método Bligh and Dyer. Instituto de salud pública de Chile. Subdepartamento laboratorios del ambiente. Sección química de alimentos. PRT: 701. 04-156. 